\title{
The Impact of Feminism in the Branch of Women's Studies: The Study of the Development of Sex according to the Theories of Gender
}

\author{
Farhana Haque* \\ University of Brunei Darussalam, Brunei \\ *Corresponding author: Farhana Haque, Academy of Brunei Studies, University of Brunei Darussalam, 1st floor, Postgraduate \\ Room (1.02), Brunei. \\ To Cite This Article: Farhana Haque. The Impact of Feminism in the Branch of Women's Studies: The Study of the Development of Sex according \\ to the Theories of Gender. Am J Biomed Sci \& Res. 2019 - 2(5). AJBSR.MS.ID.000603. DOI: 10.34297/AJBSR.2019.02.000603
}

Received: March 31, 2019 | Published: April 29, 2019

\begin{abstract}
In the branch of gender studies, the impact of feminism was noticeable. From the history of feminist movements, we can see that the feminist activists were adamant to establish women's rights same as men both at home and their work place. The history of gender has comparatively short story and its emergence became happened during the 1960s and the evolution got activated through second wave feminism. Gender inequality came to regard from both the personal relationships and in social positioning such as economically and politically, second wave feminism actually did introduce about how the issues of gender inequality got eliminated from academic disciplines, therefore they did pay the attention about how women's roles and identity were neglected and this thing occurred prior to the 1970s. The social sciences did ignore this issue of gender in general and sociology did it in a larger way.
\end{abstract}

In pre 1970s gender blind sociology only did highlight women as wives and mothers within their families but at that time this kind of differences or inequalities between men and women were not seen or recognized as sociological awareness and problems to be noted. The differences and inequalities actually happened in 1970s and especially by women sociologists, therefore they felt the urgency or need to identify and took the initiatives to examine those problems. In English literature, women's worthiness got ignored and prohibited, therefore they were searching for their authority to get the general law of great works of literature. The hegemony of a canon of great works of literature which particularly excluded women writers altogether and had nothing to say about the material and social conditions that prohibited the emergence of 'great women in this arena'. To analyses in which arena women's worthiness of study in their own right arrived and to search the clear success for feminist politics, scholars went beyond the normal boundaries of their home disciplines. Here I would like to mention [2] that moved effortlessly from literary criticism to a critique of Freud and Marx. Her perspectives later became the business of literary studies very much.

Do in 1960s and early 1970s sheer number of women have in the fields of humanities in comparison to other academic fields made it an era that was fully developed for feminist critique and also the existence of women was developed and the result of the gendered logic of the work place. In the late 1960s in US and from the mid to late 1970s in the UK that women's studies begun to develop as a specialized area of academic interest, also it was rapidly spreading elsewhere around the globe. In UK British women's studies was emerged in MA program in Kent (1980), then York and Warwick. In those places and era women's studies was included as a discrete area of study. In US (1969) such courses like women's studies begun to be taught quite spontaneously natural or careless way without substantial prior organization in many US colleges and universities. So, we can say it was a similar story in the UK and retrospectively without considering any past situations. The teachers in the field did communicate both nationally and internationally. Then they also involved in the debate about what women's studies was and could be. The first national women's studies conference took place in the UK in 1976. The scholars of women's studies were often found beyond the academy such as in the newsletters, at conferences and generally used to connect with same-minded thinkers. Their research will further prove that feminist activists and theorists did set a solid era to gain women's existence in a male dominated society and later this this got elaboration and constructive analysis though the theories of gender development.

Keywords: Gender; Sex; Feminism; Women's Studies; Theories of Gender Development

\section{Introduction}

For detecting gender differences women's studies played a very prime role. And then the segments of gender development theories eventually let us know about how the differences happens between male and female sex. To prove that fact first of all I would like to discuss about women's studies and their roles to present women both at home and in their job areas. Such as in the fields of government, non-government jobs, political field, and economic sector. In many of the women's studies there have been included 
consciousness raising (CR) component. Formal characteristics of academic study, particularly the teacher-student relationship and assessment were kept under scrutiny and other means of teaching and assessment than formal lecture or seminar, were experimented with. Women's studies mainly resided in English, history and sociology and sometimes separated individuals working within a general male- oriented curriculum. After the emergence of women's studies, it has been the work of scholars across the disciplines into one center or as the main area of MA or undergrad degrees. So, this area did develop a crystal-clear identity rather than casting a critical eye over the traditional disciplines like other male- oriented subjects. In this way it can be said that women's studies could become more broad and specific without the contestation of knowledge under patriarchy and allow assessing the value of something again such as knowledge, art and experience that had originated the basis of women's lives where the more important thing is, this study is still centered around the social sciences, arts and humanities rather than physical sciences such as engineering and medicine. But the ramification of women's studies raised as the core practices and prejudices of the latter and under scrutiny. Women's studies basically suggest a degree or study of empowerment for feminist knowledge. It has always two directions. One is within the disciplines where the critique sometimes said that men too are gendered beings. Such as the arising out of men's pro-feminist politics, therefore begun to develop in 1980s. A body of knowledge and theorizing that men as men. Consequently, books on men and masculinity proliferated in 1990s and introduced men's studies as a specialist area of academic focus. Secondly, gender studies is seen by many to open up field of women's studies beyond its beginning in the politics of women's liberation movement.

Then at the same time women's studies and men's studies became established as a specialized areas of academic inquiry broader theoretical developments begun to undermine their rationale. In postmodern and post structuralism approaches, the idea of women and men are discrete and categories that is challenged. The individual status of both groups called men and women are argued in a great way over time, space and also culture. Hence there is not huge justification for the use of the collective nouns. On the other hands, post-structuralism says women and men are considered as representation and these nouns called women and men achieved through performance and repetition than real entities. These two types of theoretical approaches have had a great impact on feminism. Women's and men's studies.

Also, these theories have been a main driver of increased notion of diversity and difference. In gender studies, the concept of gender inequality transcends not only between genders but within genders such as class, sexuality, ethnicity, age, disability, nationality, and religion and citizenship status. This is the reason about women and men's studies which known as the contested terms. Though gender issue developed as a complex, multi-faceted and multidisciplinary area, where the women studies advocates that, the rise of gender studies usually make women as invisible in the study of masculinity or male/female relations. The existing sense about the fact of women's studies continue towards social inequality that has been destroyed utterly and as a result DE politicization happens out of controversy and political violence. Some feel that women's studies has lost its confidence and way. They also feel that gender studies consider as a weaker sign, hence feminist knowledge has been controlled by the reformed academy. Women's studies have had accept that the rigid model of women do prohibit and declare inequality where gender studies is the best way of addressing this concern. In this 21st century there are number of characteristics about gender studies that remains in existence such as multi and inter-disciplinary gender studies that got profound impact on other contemporary theory and attitudes for generating knowledge and constellation method. Secondly, gender studies constitute by the methods of texts, knowledge and theorizing on and about gender. Gender studies not only confined within social, arts and humanity disciplines but also centered in the mainstream disciplines widely and enthusiastically embraced by students. Thirdly, feminism remains the core issue reason for the study of gender relation. The feminism reminds us about women as a group who were wrongly presented in both the public sphere and in the real natures. As we know gender relations continue to change so for this reason feminism as a political ideology will also be changed and find new arenas to explore. Gender studies will continue to change since the academic institutions themselves have changed noticeably in the last 30 years and in Britain, the shifting ideas of university polytechnic has had an impact on the development of women's studies from 1992. The certain increasing numbers of students were women, and also many women studies academics now the first generation to be educated in gender as students. That means women are ahead than men in this area of study called gender studies. They are in the same way correspondingly distant from heady politics and campus activism of 1960s and 1970s.

Here we can say challenges can be made from within the institution from a gendered perspective but gender studies remain dependent upon the academy for survival and for the support of feminist and gender-related research. Therefore, it is to be said that gender studies is a complex, multi-faced topic and where feminist perspectives remain the prominent thing. This branch of study is known as an academic specialism and across a range of disciplines and knowledge boundaries. So, this is not fix or straight forward but evolve during the period of writing and remains with issues of more recent and current concern. Gender studies identify about the positioning of Western industrial societies which is Britain where the white, middle class feminists working within the discipline of sociology. To detect the concepts of gender studies we got to know about come concepts such as psychoanalytical, feminism, post modernism, queer theory and cyborg. And also gender studies refers to the off-used terms such as identity politics, backlash and equality.

To sum up we can say, gender studies remain as a vibrant and productive academic activity and its effects continue to change in a broader way people think about themselves.

Universally it's decided that women are entitled to expecting and giving nutrition to their progeny, hence they have limitations to have children. Thus, women aspire to have limited number of progenies 
to keep extreme level of genes and in the end they reproduce. While on the other sides, men are not sure about their parenthood because they are uncertain to identify the name of biological father of their offspring. According to Buss, Larsen, Westen, and Semmelroth (1992), further, it has to be said that, for explaining the gender differences in mate likeliness and antagonism, evolutionary theories have been used to describe gender distinctions in jealousy and also according to Alexander, Eals and Silverman (1992), sextyped toy preferences and spatial abilities have been emphasized. Since this world is known as the kingdom of male's dominance everywhere such as at home and outside of home. They are always motivated to be more energetic and resilient than females. So, to have this type of quality society named that as spatial ability by which males are encourage to do hunting, other types of manly tasks whereas females are confined to take care of their children at home. To present the worldwide phenomenon about identifying females and males Alexander (2003) remarked that females are entitled to play or buy with feminine toys while males are likely to prefer masculine toys. Behind this Alexander gave logics that to choose masculine toys make males more masculine and teach them to do hunting successfully. Also, for him this successful hunting leads towards the visual system of males to be more perfect to track the spatial motions of objects that describe about boys' desired objects like cars. In contrary, according to Alexander (2003) for females, the society and as a whole the world has decided to forage for food and take care of their offspring. This leads women to be highly demotivated and make them sensitive for grabbing the objects like dolls and warm colors.

\section{Gender identity to recognize Sex Differences}

From the very stage of life gender identity started to shape and is not reversible by age 4 . Though the accurate reason of gender identity become unidentifiable. Biological, psychological and social variables explicitly motivate the procedure. A toddler's gender identity got interacted through genetics, prenatal and postnatal hormones which create differences in the brain and the reproductive organs as well as socialization also interact to mold a child's gender identity. All these differences actually happened though physiological processes and eventually got interact with social-learning influences to form a clear gender identity for children and gradually to the adults.

\section{Psychological and social influences on gender identity}

Gender identity is basically originated from chromosomal presence and physical appearance. But this origination of gender identity doesn't explain that psychological influences got missing. Socialization is one of the salient branches which helps a child to learn norms and roles which has created by society for male and female. Also plays important role in the establishment of a male and female child's sense of maleness and femaleness. When a female child learns she is a female and raised as a female then that child believes she is a female, whether on the other hands the situation is vice versa for a male. When a male child has been told that he is a male and raised as a male then tat male child firmly believes he is a male. The most noticeable example of notify the gender identity lies when parents trace their children's sex at first when a child give birth according to their genitals. To handle children, parents prefer to handle their female child less aggressively than their male child. By witnessing this type of activity, children get to understand or develop a crystal-clear realization whether they are female or male child. As well as they become habituated to a strong desire for adopting gender-appropriate mannerisms and attributes. This kind of realization usually happens with the age of 2 according to many scholars. We can say that biology sets the stage, but children's attachment and interaction with social environments and surroundings basically identify the nature of gender identity.

\section{Gender roles to identify Men and Women's Behaviors}

Gender roles exhibit both the cultural and personal phenomenon. These roles purposefully determine how males and females do talk, think, get dressed and interact within the sphere of society. These gender schemas are firmly weaved cognitive outlines about the meaning of masculinity and femininity. Also, the several socializing agents for example, educators, peers, dramas, movies, television, music, books and religion teach and reinforce gender roles throughout a child's whole life time. Most probably parents showed great influence in the time of their children's young age. After doing the minute research about adults and parents' mentality towards their children, it can be said that adult consider and treat female and male infants more politely. Parents do this type of behaviors to their young children themselves. There is one tradition about pampering and teaching children for fathers and mothers. For instance, fathers usually teach boys and also give them teaching how to fix and build things, while on the other hands, mothers teach girls how to cook, sew and keep house clean. By observing all these things, children get to know about their parents' approval when they face gender expectations, therefore embrace the culturally accepted the traditional roles. These conventional lessons are hugely reinforced by the most familiar socializing agents, for example 'media". In other ways, it is to be noted that, to learn gender roles always happen within the social spheres and with the values and teachings of parents and society that breed the generations through children.

\section{Theories of gender development}

In my earlier discussion I have mentioned that gender is socially learned phenomenon but didn't add what are the process actually look like. Through our spontaneous interactions, usually socialization happens, therefore this interaction is not as simple as it may look like. To analyze how the socialization occurs through interactions, gender theorists proposed five different theories of gender development.

\section{Psychodynamic}

Psychodynamic is the first and foremost theory which has got its origin in the work of Viennese Psychoanalyst, Sigmund Freud. This psychodynamic theory give emphasis on the role of the family, especially towards the mother specifically, as predominantly in forming one's gender identity. Generally, all boys and girls form their identity in relation to that of their mother. As we know girls are actually like their mothers and biologically, they consider themselves as connected her. Because girls are like their mothers 
biologically, they see themselves as connected to her. Because on the other sides, boys are biologically distinct or separate from their mother, they construct their gender identity in contrast to their mother. Boys usually resembles with their father more than mother.

\section{Symbolic interactionism}

Communication is the significant branch to identify gender development. Symbolic Interactionism (George Herbert Mead) is the one which basically concentrate towards the issue of communication. Although this branch has been evolved specifically to understand gender development and it has particular credibility. As it has to be said here that, gender has been learned through communication in cultural spheres. To comprehend the main messages of gender transformation, and whole activity of gender development, communication plays the vital role. For example, when teenage girls have been advised to sit straight and also have been told that, if the sit like that then they look like a lady and on the other sides, boys are considered as gentlemen who open doors for others. In this way girls and boys learn how to be gendered and divided themselves into the sections of masculine and feminine through several words (symbols) and have been told by others which we call interaction.

\section{Social learning}

Thirdly, the gender development theorist has presented the social learning theory which is based on outward inspirational factors and do argue about children's way of receiving positive reinforcement that they are inspired to continue their specific attribute. In this way children receive punishment which detect the signals of disapproval and get the order to stop that behavior for which they were getting disapproval. In terms of receiving reward or positive approval in gender development means that children get praise when they are involved in culturally accurate gender displays and punishment. The notion of aggressiveness always matches with the boys and it has been established in society and boys usually get acceptance or people say boys will be boys, because they got unique attitude than girls. But for girl's aggressiveness is somehow not acceptable and they have been throwing it out to their section of repository while boys have permission to show their aggressiveness in every way. Therefore, we can see boys and girls both have their own ways of learning different meanings of aggressiveness which is relate to their gender development.

\section{Cognitive learning}

From the previous theory which is social learning theory we got to know that it is based on external rewards and punishment, but cognitive learning theory is something different because this theory establishes children's gender development at their own extent. Kohlberg presented that children get to know their gender identity when they are at the age of three but can't see properly if their age become fixed is not up to the level of five or seven. This model of Kohlberg provides children a set of experienced or spoken rules about attaching to the social or cultural interactions. For doing so they can able to arrange much of their attributes and also of others. Thus, they look for role models to emulate maleness or femaleness as they grow older.

\section{Standpoint}

Standpoint is the last but not the least section of understanding gender development according to the gender development theorists. In my earlier discussion I have discussed how important is the role of culture in comprehending gender. Standpoint theory give the vital place to the issue of culture for realizing gender development. Race and class are two important identity makers which is salient to understand the gender in the process of identity formation according to the theorists Collins and Harding. The fact is that, culture and many other sections are organized hierarchically. For instance, some people do have more capital and cultural advantages than others. The most prominent example of showing the dominant culture, we can talk about the culture of supreme cultural aspects of USA. They have well-educated, upper middle-class Caucasian male who usually gets more sociopolitical privileges than the working class African American female. To understand the upper middle-class families, here the theory of standpoint plays one of the vital roles. In this way it's almost sure that different people get different type of scopes and chances according to the standpoints. They gradually grow for observing and knowing themselves in an accurate and specific ways. For instance, we can see that in middle class family's children are growing with the concept of attending college, and they also hear from other people about the moving place of them. But this kind of saying is anyhow different than the saying about going to university. So here we can take this as a norm where children perhaps grow up with the thinking of that university. According to the standpoint that exhibits less accessibility of university attendance. But in contrast with this, the children of elite class families will be asked about the league of school where they should attend. In of all these branches, children begin to construct their identity and roles in the society according to the norms, values and scopes donated by the specific standpoint.

\section{Conclusion}

Feminists were the ones who actually showed about gender disparity and presented gender as an important aspect to analyze. Thus, the impact of feminism came to the branch of gender studies, especially to the women's studies. And through their analysis about male and female sex we got to know the differences between them and how they are surviving differently at their home and work place unlike the male members. Gender originated and explored mainly by feminist sociologists. They have portrayed gender as a crucial aspect of research from the year 1970. Feminist sociologists were keeping the utmost oath to make the people understand that to what extent the issue of gender is predominated. According to them, gender is a set of all apparatus such as work, politics, law and other apparatus. Simultaneously, gender inequality has been an issue of rapidly growing apprehension. The word feminism came from the French word feminism in the 19th century. The medical term of feminism has been described as different ways such as feminization of male body or women with masculine traits.

The origin of feminism is derived from USA in the early part of 20th century. Basically, the term feminism alludes towards the notion to conceive the ideology about men and women's right to 
appeal as equal human beings from perspectives of politics, and moral issues. This term makes us remember that men and women should be treated as equal where there will be no discrimination. However, as we know feminism is a dynamic term which has been used to run different types of movements since the last two decades and also the most active task of feminism was the notion to establish the vision of equality by implanting it through law and culture. Feminism soon became understood to identify a political viewpoint of someone committed to change the social position of women. "Since then the term has taken on the sense of one who believes that women are subjugated because of their sex and that women deserve at least formal equality in the eyes of the law" [1]. Hence the feminist writers and activists shared their desire to imagine a world where women will be able to identify their potentiality as an individual person. But simultaneously women needed to think or keep in their mind that, they had no legal identity as individuals, literally unidentifiable. Therefore, all feminists agree that women suffer social and or material inequalities simply because of their biological identity and are committed to challenge this but the means by which such challenges might be made are many and various. Feminists agree on the central fact of women's subordination, most feminists regard feminism's heterogeneity as a sign of healthy debate. As a liberal feminist, Mary Wollstonecraft remarked, "it is argued that if men and women are educated equally, then it follows that they will get equal access to society" [1]. For feminists, revolution is the only answer to all the injustice by men upon women. In feminism there are some diverse branches and they often don't agree on the significance of equality. Individual feminists are those who think equality should remain under laws which are entitled to provide respect the people and property of entire human beings just the same of secondary features, for example sex, race and ethnicity. Another branch of feminism that is known as radical feminism, for them equality means socioeconomic equality. So, in this section it's all about power and wealth that are established by convention through society for erasing the historical advantages of men. These two branches of feminism prove the extreme activities within the movement. Within western society two women called Olympe de Gouges and Mary Wollstonecraft who were the pioneers to issue the rights of women during the 18th century.
They stood against the laws that made women as subordinate entity of men. Another set of historical circumstance created by an organized American feminism which has been originated abolitionist movement during the 1830s. Abolitionism has been actually referred to the radical antislavery movement. After abolitionism there is another familiar section of feminism called Second Wave feminism. Second wave feminism aimed at reform rather than revolution. Furthermore, the rise of logical branches of feminism that advocate the traditional family and orthodox values to unsharpened the historical mission and goals of feminism. Culture actually form the scheme of the essential attributes which are acceptable for men and women, besides this culture also denote about what kind of attributes are between men and women. There is a resilient connection between gender identity and culture, since both are salient and continuously contribute both in the sphere of home and outside of home in the work place and in society. In spite of that there are some significant differences from one culture to another culture. In the area of labor division culture plays the important role, it symbolizes what types of jobs are suitable for men or women. For example, in society we can see the stereotyped ideas about men and women's job sectors and also for other matters which do show how men are superior to women both at home and outside of home. Women are inferior to men in order to take any decision, they have less autonomy, no resources of their own also women have limited power to manage their actual place in their respective society and as well as at home. In Bangladesh there are some cultural barriers for women such as education and communication barriers, undernourishment and unsafe birth Practices, cultural practices based on religion, the notion of sharing different culture and religious faiths. Gender issue and supposition in a male dominated society.

\section{References}

1. Pilcher, Jane Whelehan, Imelda (2004) 50 Concepts in Gender Studies, London.

2. Millett K (1977) Sexual Politics (first published 1971), London, Virago. 